ORIGINAL ARTICLE

\title{
Can additional experienced staff reduce emergency medical admissions?
}

\author{
S Goodacre, S Mason, R Kersh, A Webster, N Samaniego, F Morris
}

Emerg Med J 2004;21:51-53

See end of article for authors' affiliations

.....................

Correspondence to:

Dr S Goodacre, 87A

Sydney Road, Sheffield, S6

3GG, UK; s.goodacre@

sheffield.ac.uk

Accepted for publication 20 March 2003
Background: Increases in emergency medical admissions are placing a strain upon hospitals throughout the world. The aim of the study was to evaluate the effect of a new post, the "A\&E physician", upon emergency medical admissions to a hospital.

Methods: For six months the A\&E physician workload was audited and a randomised controlled comparison undertaken. Days were randomised to "A\&E physician present" or "A\&E physician absent". The A\&E physician recorded details of all patients referred for medical admission, any intervention made, and their disposal from A\&E. Routine hospital data compared the mean daily number of medical admissions, non-medical admissions, and referrals to other hospitals.

Results: 124 days were randomised: 59 to A\&E physician present, 65 to A\&E physician absent. The A\&E physician received 581 referrals and intervened in the management of 142 (24\%). Of these, 80 were discharged home, apparently saving 1.4 admissions per day. However, randomised comparison showed that presence of the A\&E physician was associated with a reduction of only 0.7 medical admissions per day $(95 \% \mathrm{Cl}-1.7$ to $3.2, \mathrm{p}=0.561)$, and an increase of 1.1 non-medical admissions $(95 \% \mathrm{Cl}-0.2$ to 2.3 , $\mathrm{p}=0.09)$ and 0.3 transfers to other hospitals per day $(95 \% \mathrm{Cl}$ zero to $0.6, p=0.09)$. Overall, hospital admissions were increased by 0.9 per day when the A\&E physician was present $(95 \% \mathrm{Cl}-1.8$ to 3.6 , $\mathrm{p}=0.5$ ).

Conclusion: Despite receiving many referrals and discharging a substantial proportion of these patients home, the A\&E physician did not significantly change emergency medical admissions and may have increased admissions to other specialties.
A ccident and emergency (A\&E) departments in the United Kingdom are undergoing substantial organisational changes in an attempt to deal with growing problems of over-crowding and prolonged waiting times. ${ }^{12}$ Innovative ways of organising and delivering services are being introduced in many departments. ${ }^{34}$ Good practice dictates that these innovations should be subject to evaluation. However, if evaluation is limited to a simple audit of the new service, it will be impossible to determine whether the new service is genuinely tackling the problems of the department or simply duplicating current work. This study presents a simple, practical way of evaluating an organisational change in the A\&E department.

In response to concerns regarding increasing numbers of emergency medical admissions, ${ }^{5}$ the Northern General Hospital A\&E department created a new post: the A\&E physician. This role was filled by a middle grade doctor with postgraduate training in both general medicine and A\&E (RK). A person was appointed to the post for six months but duties were shared by cross covering with middle grade doctors in A\&E and general medicine (AW and NS). All three doctors had passed the Membership of the Royal College of Physicians examination and had received general professional training in A\&E and general medicine.

Their role was to review patients referred from A\&E for medical admission and, using their experience, access to diagnostic tests and outpatient clinics, divert appropriate cases away from medical admission. They worked from 9 am to $6 \mathrm{pm}$ on weekdays, but not at weekends. Our evaluation aimed to determine whether they were successful in reducing medical admissions.

\section{METHODS}

Evaluation involved audit of cases referred to the A\&E physician and cluster randomised comparison of service delivery with, and without, the A\&E physician.

\section{Audit of cases referred to the A\&E physician}

The A\&E physician recorded the following details for all cases referred from A\&E:

- Management undertaken: investigations arranged and drugs prescribed

- Final destination from A\&E

These data were then analysed to determine the workload of the A\&E physician and the number of potential admissions diverted to discharge home and/or to outpatient follow up.

\section{Cluster randomised evaluation}

Days of the week were randomly allocated to either the A\&E physician being present, or the A\&E physician being absent. Block randomisation was used so that A\&E physician duty rosters could be appropriately organised. Monday to Friday blocks were created, with selected days allocated to A\&E physician present and others to A\&E physician absent. Each week was then allocated by random selection of one of these blocks. Other A\&E staffing rosters were organised without knowledge of, or reference to, the A\&E physician roster.

The primary outcome measure was the daily number of emergency medical admissions from the A\&E department. Secondary outcome measures were: the daily number of nonmedical A\&E admissions to the Northern General Hospital (excluding orthopaedic admissions) and daily transfers to 


\begin{tabular}{|lcc|}
\hline \multicolumn{2}{l}{ Table 1 Interventions undertaken by the A\&E physician } \\
\hline Intervention & Discharged ( $\mathbf{n}=\mathbf{8 0}$ ) & Admitted ( $\mathbf{n = 6 2 )}$ \\
\hline Venous blood tests & 30 & 36 \\
Arterial blood gas measurements & 7 & 3 \\
Radiograph & 11 & 29 \\
Bacteriology & 4 & 0 \\
Computed tomography & 9 & 29 \\
Echocardiogram & 7 & 1 \\
Lower limb Doppler scan & 3 & 0 \\
Advice & 38 & 26 \\
Electrocardiograph & 21 & 3 \\
Antibiotics & 19 & 5 \\
Analgesics & 1 & 0 \\
Cardiac drug & 16 & 3 \\
Other drug & 10 & 0 \\
\hline
\end{tabular}

other hospitals. All data were routinely recorded by the A\&E department. Assuming that there would be 40 medical admissions per day (standard deviation $=6$ ), it was estimated that randomisation of 120 days would give $80 \%$ power to detect a difference of three admissions per day $(\alpha=0.05)$. Cluster level analysis was performed, using the daily number of admissions as the unit of analysis. Regression was planned to adjust for confounding by day of week (Mondays were expected to be busier) and daily number of A\&E attendances.

The North Sheffield Research Ethics Committee granted ethical approval for the study.

\section{RESULTS}

After excluding weekends and bank holidays, 124 study days were randomised, 59 to A\&E physician present and 65 to A\&E physician absent. The mean daily rate of attendance at A\&E was 293 attendances per day (SD 31, range 240 to 377), the mean daily total number of admissions was 57 (SD 9, range 37 to 87 ), and the mean daily number of medical admissions was 36 (SD 8, range 20 to 58).

\section{A\&E physician workload}

The A\&E physician received 581 referrals from A\&E staff: a mean of 9.8 referrals per day. The A\&E physician intervened in the management of 142 of these patients $(24 \%$ of those referred, 2.4 patients per day). Table 1 outlines the interventions. After intervention, 80 patients were discharged and 62 were admitted. Thus the A\&E physician was responsible for discharging 1.36 patients per day who the initial assessing doctor had planned to admit. After discharge, 21 of 80 patients had no follow up arranged, 19 had follow up arranged with their GP, 30 had outpatient follow up arranged, and 10 had other forms of follow up.

\section{Cluster randomised comparison}

There were more attendances at the A\&E department on days when the A\&E physician was present (mean daily attendances 305 versus 297, $p=0.129$ ). The daily rate of attendance at A\&E was a highly significant, independent predictor of daily medical admissions $(p<0.001)$. After adjusting for the daily rate of attendance, medical admissions were more frequent on Mondays $(p=0.047)$. No other day of the week was associated with a significant difference in medical admission rate.

Table 2 compares the mean daily admissions on days when the A\&E physician was present or absent. The difference between the means was adjusted to take into account baseline differences in the daily rate of attendances to the A\&E department and the days of the week randomised to A\&E physician present or absent. The adjusted difference in admission rate is shown along with $95 \%$ confidence intervals. The A\&E physician had only a small (non-significant) effect upon medical admission rates, and no effect upon total admission rates. There was some weak evidence that presence of the A\&E physician was associated with increased rates of referral to other (non-medical) specialties and to other hospitals.

\section{DISCUSSION}

Despite receiving a substantial number of referrals and discharging a substantial proportion of these patients home, the A\&E physician did not significantly change the emergency medical admission rate and may even have increased admissions to other specialties. This suggests that the A\&E physician was being referred patients that would otherwise have been discharged home. Simple audit of the role of the A\&E physician suggested that they were performing a

\begin{tabular}{|c|c|c|c|c|c|}
\hline Outcome & $\begin{array}{l}\text { A\&E physician } \\
\text { present }\end{array}$ & $\begin{array}{l}\text { A\&E physician } \\
\text { absent }\end{array}$ & $\begin{array}{l}\text { Adjusted } \\
\text { difference* }\end{array}$ & $95 \% \mathrm{Cl}$ & p Value \\
\hline Total admissions & 60.2 & 57.7 & 0.9 & -1.8 to 3.6 & 0.499 \\
\hline Medical admissions & 39.3 & 38.8 & -0.7 & -3.2 to 1.7 & 0.561 \\
\hline $\begin{array}{l}\text { Orthopaedic } \\
\text { admissions }\end{array}$ & 4.8 & 4.9 & 0.1 & -0.6 to 0.8 & 0.852 \\
\hline $\begin{array}{l}\text { Other non-medical } \\
\text { admissions }\end{array}$ & 10.1 & 8.8 & 1.1 & -0.2 to 2.3 & 0.088 \\
\hline $\begin{array}{l}\text { Transfers to other } \\
\text { hospitals }\end{array}$ & 5.8 & 5.0 & 0.3 & 0 to 0.6 & 0.090 \\
\hline
\end{tabular}

*Negative difference indicates that presence of the A\&E physician reduced admissions. 
valuable function, but cluster randomised evaluation revealed that this did not actually affect admission rates.

Cluster randomised methods are frequently used to evaluate changes in the organisation and delivery of services. ${ }^{67}$ However, the impact of organisational changes, such as employing additional staff members, may be difficult to generalise between settings. We have shown that cluster randomised methods can be used in a busy A\&E department to evaluate a specific change to service delivery. The large number of patients presenting to A\&E means that, even using cluster techniques, a single department may see sufficient numbers to provide reasonable statistical power.

This approach does have some limitations that must be appreciated. Clustering of data reduces statistical power, thus a small reduction in the admission rate associated with the A\&E physician cannot be excluded. Reducing medical admissions is not the only potentially valuable role for the A\&E physician. It may be that, although the overall admission rate was unchanged, admission decisions were more appropriate when the A\&E physician was present. Finally, cluster randomisation does not allow allocation concealment, so staff will be aware of the intervention under investigation. Although we made specific effort to ensure that A\&E physician availability did not change other staffing rosters, we cannot exclude the possibility that senior or middle grade staff performed more non-clinical duties when the A\&E physician was present.

In summary, by introducing a change to departmental organisation in a cluster randomised manner, we have provided a more reliable estimate of the true value of this change than by simple audit alone. This approach is simple and feasible, and should be widely used to evaluate the many changes in service delivery currently taking place in the NHS.

\section{Contributors}

The study idea was conceived by SG and developed by SG, SM, and FM. All the authors contributed to the study design. Data were collected by SG, RK, AW, and NS, and analysed by SG. SG wrote the first draft of the paper. All the authors contributed to the final draft.

\section{Authors' affiliations}

S Goodacre, S Mason, R Kersh, A Webster, F Morris, Accident and

Emergency Department, Northern General Hospital, Sheffield, UK

S Goodacre, S Mason, Medical Care Research Unit, University of

Sheffield, Sheffield, UK

N Samaniego, Department of Care for the Elderly, Royal Hallamshire Hospital, Sheffield, UK

Funding: this project was funded by the Northern General Hospital Accident and Emergency Department. SG was supported by a Trent R\&D Health Services Research Fellowship.

Conflicts of interest: none declared.

\section{REFERENCES}

1 Audit Commission. Acute hospital portfolio review of national findings: accident and emergency. London: The Audit Commission, 2001.

2 Department of Health. Reforming emergency care. London: Department of Health, 2001.

3 Cooke MW, Wilson S, Pearson S. The effect of a separate stream for minor injuries on accident and emergency department waiting times. Emerg Med J 2002; 19:28-30.

4 Goodacre SW, Morris FM, Campbell S, et al. A prospective, observational study of a chest pain observation unit in a British hospital. Emerg Med J 2002;19:117-21.

5 Capewell $\mathbf{S}$. The continuing rise in emergency admissions: explanations and responses must be properly evaluated. BMJ 1996;312:991-2.

6 Campbell M, Fitzpatrick R, Haines A. Framework for design and evaluation of complex interventions to improve health. BMJ 2000;321:694-6.

7 Ukoumunne OC, Gulliford MC, Chinn S, et al. Methods for evaluating areawide and organisation-based interventions in health and health care: a systematic review. Health Technol Assess 1999;3 (suppl). 